\title{
Evaluation of Surgical Procedures in Emergency Cases during Pandemic of Covid 19 \\ Marwan Mansour Borham
}

\author{
Departments of General Surgery, Faculty of Medicine, Al-Azhar University, Egypt \\ Corresponding author: Marwan Mansour Borham, Mobile: (+20) 01090480337, E-Mail: marwanborham74@ gmail.com
}

\begin{abstract}
Background: Covid 19 is worldwide problem defined as infection caused by corona virus. World Health Organization defined it as a pandemic disease that can be controlled. It is public health problem. The regimen and ways of management of surgical patient changed after epidemic attack of Covid 19

Objective: To evaluate the procedures, infection control and follow up in emergency patient during attack of Covid 19.

Patient and methods: Cross sectional study done on 35 patient selected in emergency room in Al-Hussain University Hospital during the period from the $1^{\text {st }}$ May to $1^{\text {st }}$ August, done on emergency cases only and elective cases were excluded during attack of Covid 19.

Results: Total number of 35 patient, through them 28 patient (80\%) were discharged without complication, 10 patient $(28.6 \%)$ of them were admitted to ICU, 13 patient (37.1\%) has postoperative morbidity, 3 patient $(8.6 \%)$ died from postoperative complication. 3 patient were postoperatively Covid 19 positive, all discharged patient were negative for Covid 19 and no positive cases were found during follow up.

Conclusion: This study was done on the surgical patient in the hospital not on positive patient for Covid 19 and it described the best way to treatment and isolation of the surgical patient during attack of Covid 19. Patient were successfully managed and discharged with follow up for 14 days negative result of Covid 19.
\end{abstract}

Keywords: Covid 19, Emergency cases, General surgery, Health service, Recommendation and Pandemic

\section{INTRODUCTION}

First case of Covid 19 was discovered in Wuhan city in China in December 2019 as outbreak of pneumonia of unknown cause ${ }^{(1)}$. In January 2020 the Chines government discovered the cause of pneumonia, which was corona virus $(\text { sars-cov- } 2)^{(2)}$. In February 2020, the World Health Organization named the outbreak of disease corona virus disease or Covid $19^{(3)}$. In March, World Health Organization declared that outbreak of corona Covid 19 virus is pandemic ${ }^{(4)}$.

Covid 19 is worldwide problem defined as infection caused by corona virus. World health organization, defined it as a pandemic disease that can be controlled and it is public health problem as Covid 19 spread across the world ${ }^{(5)}$.

Egypt considered as part of the issue, the especial hospital for treatment of the pandemic problem is infectious, as epidemic spread of many disease happened before like Spanish flu, 1918-1919, which killed an estimated 40 million people, and the HIV/AIDS epidemic which has caused widespread morbidity and mortality ${ }^{(6)}$.

The number of patient admitted to emergency unit in our hospital diagnosed or suspected Covid 19 was increasing, with progressive increasing spread of the disease. In our country the number of patients having surgical emergency was increased, the elective cases at time of break should be postponed until the pandemic subsides ${ }^{(7)}$.

Emergency surgical patient cannot wait or postponed. There was increased incidence of mortality than usual, in time of Covid 19 crises during the epidemic attack. Absence of previous history of Covid epidemic turn the deal with surgical cases very difficult and strict, shortage of literature about Covid 19 before made plane for response also difficult ${ }^{(\mathbf{8 , 9})}$.

Covid 19 has changed some protocols inside the operating theater. The virus was detected in blood, saliva and peritoneal fluid in patient underwent laparotomy ${ }^{(\mathbf{1 0 )}}$. There was also asymptomatic carrier reported during the time of epidemic surgery. Uses of diathermy or laparoscopic air may spread the virus from peritoneal fluid and risk the staff in operating theater for contaminations ${ }^{(11,12)}$.

The Royal Colleges of Surgeons in Ireland and Great Britain recommended a risk reduction strategy for managing these patients, including use of personal protective equipment (PPE), opting for conservative management where possible, and choosing open rather than laparoscopic operations unless the laparoscopic approach may have substantial clinical benefits for the patient that give priority to take precautions against Covid 19 for the staff and the emergency patient ${ }^{(13)}$.

The pandemic affect the healthcare system and methods of treatment. As we were studying the best way for facing the Covid19 in general and Covid 19 especially in surgical patient we should make plane for the future similar crises

The aim of the present study was to evaluate the recommendation for the emergency surgical patient with Covid 19 and their follow up in our hospital. The aim of this study was also to examine the impact of 
Covid 19 on the number of patients presenting to our institution with emergent surgical illnesses or requiring emergency general surgical procedures.

\section{PATIENTS AND METHODS}

This study was done on 35 patients admitted to our hospital, Surgical Department, Al-Hussain University Hospital as emergency cases from the time of $1^{\text {st }}$ May 2021 to $1^{\text {st }}$ August 2021 during attack of Covid 19 pandemic. During this time the health care authority declared that our country was exposed to the third pandemic attack of Covid 19 and asked every health care provider or hospital to start to arrange their work according to the new situation.

The surgical team scheduled the patients according their presentations as emergency cases, collecting data of demography from the electronic system in admission unit, including age, sex, presentation, preoperative investigations, anesthetic procedures, surgical procedures, length of hospital stay, duration of operation, intensive care unit admission, postoperative morbidity and mortality, postoperative Covid 19 suspicion.

All patients were assessed for suspicion or having Covid 19 before admission and after discharge. After start of the crises the hospital infection control team established especial unit for examination of all emergency patients before contacting with the hospital staff. And then filtering the patients according to the unit they belong to it. The surgical patients were referred to our unit and we proceed as follows: All suspected or approved patients were evaluated and managed in isolated parts, with separation between suspected, infected and approved Covid 19 patients.

After diagnosis and investigation the patient were prepared for or with complete isolation, transferring the patient to the operating room in limited way without contacting the hospital employee, the operating room team were wearing especial protecting clothe; personal protecting equipment (PPE) as rapid as possible to avoid wasting time inside the operating theater.

The anesthetic procedures were carried out with the operative team wearing an N95 protective mask with a surgical mask over it, a surgical box gown and protective goggles. The anesthetic team dealing with the patient should be with expert and rapid hand and decision. If the patient received general anesthesia intubation with laryngoscope, without mask ventilation, nasal oxygen was enough in induction and recovery of anesthesia. Recovery was advised to be done in operating room without entering the recovery room. They were pushed to the surgical isolation unit or ICU. The surgical staff should uses the PPE (liquidtight gowns, surgical masks over N95, protective goggles and gloves (double), as personal protection.

The responsibility for postoperative care was on the isolation surgical team with full precautionary measures.
At the time of discharge. The patients were given the recommendation that they should adhere to a 14day isolation period. On the $14^{\text {th }}$ day after discharge, these patients were called by phone, to gain information. All procedures were done with complete isolation of the patients, and protection of the staff.

\section{Ethical consent:}

An approval of the study was obtained from AlAzhar University Academic and Ethical Committee. Every patient signed an informed written consent for acceptance of the participation in the study. This work has been carried out in accordance with The Code of Ethics of the World Medical Association (Declaration of Helsinki) for studies involving humans.

\section{Statistical analysis}

The collected data were coded, processed and analyzed using the SPSS (Statistical Package for the Social Sciences) version 22 for Windows ${ }^{\circledR}$ (IBM SPSS Inc, Chicago, IL, USA). Frequencies and percentages have been employed to represent qualitative data. Quantitative data were presented as means.

\section{RESULTS}

The general character and demographic data are shown in table 1 .

Table (1): General character and demographic distribution

\begin{tabular}{|l|c|c|}
\hline Age & $15-76$ & $\begin{array}{c}\text { Mean } \\
\text { age } \\
36.8\end{array}$ \\
\hline Sex & 19 male & $\begin{array}{c}16 \\
\text { female }\end{array}$ \\
\hline Male & 19 & $54.3 \%$ \\
\hline Female & 16 & $45.7 \%$ \\
\hline Time of operation & $\begin{array}{c}30-160 \\
\text { minutes }\end{array}$ & \\
\hline Comorbidity & 13 & $37.1 \%$ \\
\hline Hospital stay & $2-24$ & \\
\hline Preoperative chest X-ray & 35 patients & $100 \%$ \\
\hline Preoperative CT & 16 patients & $45.7 \%$ \\
\hline $\begin{array}{l}\text { ICU admission } \\
\text { postoperative }\end{array}$ & 10 & 28.6 \\
\hline Postoperative intubation & 8 & $22.9 \%$ \\
\hline $\begin{array}{l}\text { Postoperative positive } \\
\text { Covid 19 test }\end{array}$ & 3 & 8.6 \\
\hline Wound sepsis & 6 & $17.1 \%$ \\
\hline $\begin{array}{l}\text { Suspected postoperative } \\
\text { Covid 19 }\end{array}$ & 3 & $8.6 \%$ \\
\hline $\begin{array}{l}\text { Preoperative CT for } \\
\text { suspected Covid 19 }\end{array}$ & 0 & 0 \\
\hline
\end{tabular}


The most common causes of admission was acute appendicitis in 6 patients of 35 total, about $17.1 \%$. Two of them were presented with manifestation of diffuse peritonitis fever, nausea, vomiting, abdominal pain, severe tenderness over the right iliac fossa with rebound tenderness, under cover of broad spectrum antibiotics, all were treated with open appendectomy. 4 patients had post traumatic splenic injury (11.4\%). 4 patients had different abscess place treated by incision and drainage. Three patients with irreducible hernia, about $8.6 \%$, one of them was on anticoagulant therapy developed hematoma at the site of operation managed by drainage. Three patients $(8.6 \%)$ with perforated viscous were operated upon by exploration and repair of the intestinal perforation after refreshment of the edges primary repair done.

Three patients, about $8.5 \%$, with acute cholecystitis were treated by conservative treatment. Three patients with sigmoid volvulus were treated by resection of the sigmoid colon. 2 patients $(5.7 \%)$ with hematemesis, due to peptic ulcer and one due to esophageal varices were treated by upper endoscopy, both of them needed blood transfusion. One patient $(2.9 \%)$ with thrombotic piles was treated by hemorrhoidectomy. One patient (2.9\%) with obstructive jaundice was treated by using ERCP. Tow patients with adhesive intestinal obstruction were treated with adhesiolysis. One patient with mesenteric vascular occlusion was managed with exploration and resection anastomosis. 3 patients with sigmoid volvulus were treated with exploration and sigmoid resection with temporary colostomy fashioned then after 6 weeks closure of colostomy was done of the sigmoid colon. One patient (2.9\%) with intussusception was treated by resection anastomosis of the terminal ileum. One patient with right diabetic foot gangrene was treated with below knee amputation. All the patients were operated upon with emergency in Emergency Department with no manifestation or suspicion of Covid 19. After discharge of those patient, no one has manifestation of Covid 19 through the next 14 days of follow up, no elective cases included in this study, also children below 15 years were excluded (Table 2).
Table (2): Diagnosis and type of operation

\begin{tabular}{|l|l|c|}
\hline \multicolumn{1}{|c|}{ Diagnosis } & \multicolumn{1}{|c|}{ Operation } & $\begin{array}{c}\text { Number of } \\
\text { the patient }\end{array}$ \\
\hline Acute appendicitis & Open appendectomy & 6 \\
\hline Splenic injury & Splenectomy & 4 \\
\hline Abscess & Incision and drainage & 4 \\
\hline Irreducible hernia & Herniorrhaphy & 3 \\
\hline Perforated viscous & Exploration & 3 \\
\hline Acute cholecystitis & Conservative & 3 \\
\hline Hematemesis & Upper endoscopy & 2 \\
\hline Thrombotic piles & Hemorrhoidectomy & 1 \\
\hline $\begin{array}{l}\text { Obstructive jaundice } \\
\text { Endoscopic Retrograde }\end{array}$ & 1 \\
\hline $\begin{array}{l}\text { Adhesive intestinal } \\
\text { obstruction }\end{array}$ & Adhesiolysis & 2 \\
\hline $\begin{array}{l}\text { Mesenteric vascular } \\
\text { occlusion }\end{array}$ & Exploration & 1 \\
\hline Sigmoid volvulus & Resection & 3 \\
\hline Intussusception & Resection anastomosis & 1 \\
\hline $\begin{array}{l}\text { Right diabetic foot } \\
\text { gangrene }\end{array}$ & Amputation & 1 \\
\hline
\end{tabular}

Total $=35$

Two patients were admitted to intensive care unit (5.7\%), general surgical services 2 patients $(5.7 \%)$, the total mortality were 3 patients $8.6 \%$. The number of patients discharged without complication was 28 patient $80 \%$ (Table 3).

Table (3): Current status

\begin{tabular}{|l|c|c|}
\hline & $\mathbf{N}$ & $\mathbf{\%}$ \\
\hline Intensive care unit & 2 & $5.7 \%$ \\
\hline General surgery service & 2 & $5.7 \%$ \\
\hline Mortality & 3 & $8.6 \%$ \\
\hline Discharge without problem & 28 & $80 \%$ \\
\hline
\end{tabular}

\section{DISCUSSION}

During the peak of pandemic attack of Covid 19, as the virus continues spreading, the health care services were affected all over the world. The infection control team changed the way of management in the general surgical department. There was sudden and big decrease in the number of surgical patient of $50 \%$ in the number of patients needs admission in Surgical Department in our hospital in comparison with Emergency Department in Ireland 45.4\% during the same time ${ }^{(\mathbf{1 4})}$, also three was decrease in Emergency Department admission in Italy and UK ${ }^{(15)}$.

Other than surgical department, there was reduction in the number of myocardial infarction by 25 to $50 \%{ }^{(16)}$, but the causes of decrease in number of attendance to the hospital during period of Covid 19 is the fear of catching infection from the hospital during the Covid 19 outbreak. The reasons for the decline in patients presenting with non-Covid 19 illnesses to our hospital and internationally are unclear, and likely multifactorial. One proposed hypothesis is that patients 
were reluctant to attend hospitals for care of non Covid 19 illnesses because of fear of acquiring Covid 19 infection ${ }^{(17)}$.

From this study we noticed that emergency surgery still can be done at the time of viral outbreak or pandemic attack of Covid 19 if the protective measures and precautions were taken against infection spread. On other hand the research of epidemiology, pathology and treatment of patient with Covid 19 and the effect on public health algorithm for surgical treatment of patient with suspicions or diagnosed of Covid 19 of secondary impotence ${ }^{(18)}$.

Other researches from anesthesiologists have been published about the way to protect their self and precautions at time of intubation during the period of Covid $19^{(19)}$, also the recommendations done for the surgical patient suspicious or diagnosed with Covid 19 (20)

In spite of surgical operations done for the patient during Covid 19 attack the telemedicine and remote consultation increases internationally ${ }^{(21)}$. In spite of that big number of Covid 19 patient are asymptomatic, they are considered infected patient and taken care as positive cases. The virus is transmitted by droplet infection also can stay on surface for hours or days as source of infection ${ }^{\mathbf{( 1 9 )}}$.

As the surface contaminated from the patients, the healthcare staff avoided the contact with this surface to avoid transmission of the infection to themselves or to the others ${ }^{(22)}$. All surfaces were disinfected in the operating theater and spacing between the operations to allow enough time for sterilizations, decreasing the number of anesthesiologists and surgeons as much as possible inside the theater using the minimum number of staff to manage the operation.

Also the use of laparoscopy in emergency cases still in controversies ${ }^{(23)}$. The decrease in number of patients also recommended by treating some patient with watch and wait strategy as nonspecific abdominal pain in right iliac fossa with oral antibiotics, or cellulites ${ }^{(24)}$.

We did not do any cases of laparoscopic emergency but in other studies they used laparoscopy in emergency as appendicitis, diagnostic laparoscopy and laparoscopic colectomy. But with especial care of laparoscopic gas avoidance of direct contact with gas as Covid 19 can be transmitted through peritoneal fluid and gas $^{(\mathbf{2 5})}$. As uses of laparoscopy reduce the time of hospital stay we recommend to use it if possible in emergency cases with over care of contamination of Covid 19 and under experienced surgeon.

Review by Di Saverio et al. (20) it was recommended to do tests for Covid 19 for all surgical patient whom will underwent surgical emergency but in our study we didn't do even in suspected case because the result will delay, and the result will not affect the decision ${ }^{(26)}$.

During the Covid 19 pandemic attack surgical patient should be considered as positive cases until proved otherwise, so recommended preoperative screening should be done to avoid worse operative result and postoperative complications ${ }^{(27)}$. The Italian Hospital Surgeons Association (ACOI) recommend routine preoperative chest $\mathrm{CT}$ as routine ${ }^{(28)}$. In our study absences of routine preoperative screening obligated us to uses complete protective measures, PPE and all precaution to protect the healthcare provider ${ }^{(29)}$. Postoperatively the surgical team and the other patient contacts should continue on the same preoperative measures with complete protective measures that doesn't underestimate even if the patient is negative ${ }^{(\mathbf{1 8})}$.

For the complicated patient returned back to hospital, patient should be considered potentially infected and should be dealt with complete protective measures because contacts with visitors and other persons outside the hospital. During the time of the pandemic all elective and endoscopic procedures have been postponed due to extended duration of pandemic. The limitation of this study is due to limitation of the number of patient and single hospital study.

\section{CONCLUSION}

After declaring the pandemic of Covid 19 many surgical management recommendation is insufficient thus continuous updating is important. So isolation of Surgical Department is important in reduction of the number of infection by using PPE, preoperative CT chest and abdomen, decrease the contact between staff and the patient. The patient with emergency surgery and patient with Covid 19 are treated successfully without affecting each other by following protective measures and the positive data are supported by follow up 14 days after discharge.

\section{Financial support and sponsorship: Nil. Conflict of interest: Nil.}

\section{REFERENCES}

1. Li Q, Guan X, Wu P et al. (2020): Early transmission dynamics in Wuhan, China, of novel coronavirusinfected pneumonia. New Engl J Med., 382(13):1199207.

2. Tan W, Zhao X, Ma $X$ et al. (2020): A novel coronavirus genome identified in a cluster of pneumonia cases- Wuhan, China 2019-2020. China CDC Weekly, 2(4):61-2.

3. World Health Organization (2020): Director-General's remarks at the media briefing on $2019-\mathrm{nCoV}$ on 11 February 2020. https:// www.who.int/dg/speeches/ detail/who-director-general-s-remar ks-at-the-mediabriefing-on-2019-ncov-on-11-february-2020.

4. World Health Organization (2020): Director-General's opening remarks at the media briefing on Covid-19-11 March 2020. https:// www.who.int/dg/speeches/ detail/who-director-general-s-opening-remarks-at-themedia-briefing-on-Covid-19---11-march 2020.

5. Centers for Disease Control and Prevention (2020): Coronavirus disease 2019 (COVID-19) situation 
summary. https://www.cdc.gov/ coronavirus/2019ncov/summary.

6. Gok A, Eryılmaz M, Ozmen M et al. (2020): Recommendations for trauma and emergency general surgery practice during COVID-19 pandemic. Ulus Travma Acil Cerrahi Derg., 26(3):335-42.

7. World Health Organization (2020): Report on global surveillance of epidemic prone infectious diseases introduction. Switzerland, Geneva. https://apps. who.int/iris/ handle/10665/66485

8. Ti L, Ang L, Foong T et al. (2020): What we do when a COVID-19 patient needs an operation: operating room preparation and guidance. Can J Anesth., 67(6):756-758.

9. COVIDSurg Collaborative (2020): Mortality and pulmonary complications in patients undergoing surgery with perioperative SARS-CoV-2 infection: an international cohort study. Lancet, 396(10243): 27-38.

10.Bonifazi C, Paparusso A, Barletta G et al. (2020): Collection of documents containing urgent measures regarding the containment and management of the emergency epidemiological from COVID-19. Collection of documents issued by the Government, Pp. 1-20. https://www.gazzettaufficiale.it/ eli/id/2020/03/22/ $20 \mathrm{~A} 01807 / \mathrm{sg}$.

11. Coccolini F, Tartaglia D, Puglisi A et al. (2020): SARS-CoV-2 is present in peritoneal fluid in COVID-19 patients. Ann Surg., 272(3): 240-42.

12.Zheng M, Boni L, Fingerhut A (2020): Minimally invasive surgery and the novel coronavirus outbreak: lessons learned in China and Italy. Ann Surg., 272(1):56.

13. Royal College of Surgeons (2020): Updated general surgery guidance on COVID-19. Royal College of Surgeons in Ireland; 2020. https://www.rcseng.ac.uk/ coronavirus/joint-guidance-for-surgeons-v2/

14. Brick A, Walsh B, Keegan C et al. (2020): COVID-19 and emergency department attendances in Irish public hospitals. Economic and Social Research Institute; 2020. https://www.esri.ie/system/files/publications/QEC2020S UM_SA_lyons.pdf

15. Lazzerini M, Barbi E, Apicella A et al. (2020): Delayed access or provision of care in Italy resulting from fear of COVID-19. Lancet Child Adolesc Health, 4(5):1-10.

16. Solomon M, McNulty E, Rana J et al. (2020): The Covid-19 pandemic and the incidence of acute myocardial infarction. N Engl J Med., 383(7):691-93.

17.Long L, Corsar K (2020): The COVID-19 effect: number of patients presenting to the Mid Yorkshire
Hospitals OMFS team with dental infections before and during the COVID-19 outbreak. Br J Oral Maxillofac Surg., 58(6):713-714.

18. Kamer E, Çolak T (2020): What to do when a patient infected with COVID-19 needs an operation: a presurgery, peri-surgery and post-surgery guide. Turk J Colorectal Dis., 30: 1-8.

19. Wen X, Li Y (2020): Anesthesia procedure of emergency operation for patients with suspected or confirmed COVID-19. Surg Infect (Larchmt), 21(3):299302.

20.Di Saverio S, Pata F, Gallo G et al. (2020): Coronavirus pandemic and colorectal surgery: practical advice based on the Italian experience. Colorectal Dis., 22(6):625-634.

21.Smith W, Atala A, Terlecki R et al. (2020): Implementation guide for rapid integration of an outpatient telemedicine program during the COVID-19 pandemic. J Am Coll Surg., 231(2):216-222.

22.van Doremalen $\mathrm{N}$, Bushmaker $\mathrm{T}$, Morris $\mathrm{D}$ et al. (2020): Aerosol and surface stability of SARS-CoV-2 as compared to SARS-CoV-1. N Engl J Med., 382(16): 1564-67.

23. Yu G, Lou Z, Zhang W (2020): Several suggestion of operation for colorectal cancer under the outbreak of Corona Virus Disease 19 in China. Zhonghua Wei Chang Wai Ke Za Zhi., 23(3):9-11.

24. Sullivan T, de Barra $E$ (2018): Diagnosis and management of cellulitis. Clin Med., 18(2):160-163.

25. Morris S, Fader A, Milad M et al. (2020): Understanding the "scope" of the problem: why laparoscopy is considered safe during the COVID-19 pandemic. J Minim Invasive Gynecol., 27(4):789-791.

26. Karaca A, Özmen M, Uçar A et al. (2020): General surgery operating room practice in patients with COVID19. Turk J Surg., 36(1): 1-5.

27. Ai T, Yang Z, Hou H et al. (2020): Correlation of chest CT and RT-PCR testing in coronavirus disease 2019 (COVID-19) in China: a report of 1014 cases. Radiology, 26: 200642.

28. Association of Italian Hospital Surgeons (2020): Intercollegiate general surgery guidance on COVID-19. https://www.acoi.it/ dettaglio.aspx? $\mathrm{id}=4778$.

29. COVID-19 Resource Center (2020): COVID 19: Considerations for optimum surgeon protection before, during, and after operation. American College of Surgeons, Pp. 1-3.. https://www.facs.org/Covid19/clinical-guidance/surgeon-protection. 